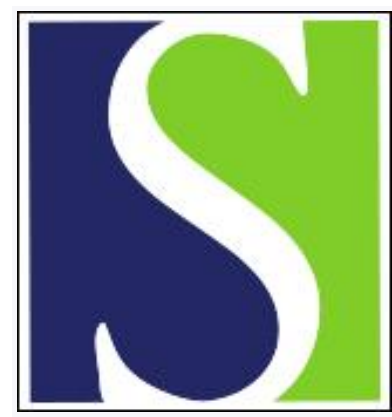

Scand J Work Environ Health 2013;39(5):477-485

https://doi.org/10.5271/sjweh.3353

Published online: 25 Feb 2013, Issue date: 01 Sep 2013

Do work factors modify the association between chronic health problems and sickness absence among older employees?

by Leijten FRM, van den Heuvel SG, Ybema JF, Robroek SJW, Burdorf A

The key practical implications of this study are that higher job demands and lower autonomy increase the risk of sickness absence among persons with common chronic health problems, and thus that focus on these work-related factors should be central in the promotion of sustainable employability.

Affiliation: Department of Public Health, Erasmus MC, PO Box 2040, 3000 CA Rotterdam, The Netherlands. a.burdorf@erasmusmc.nl

Refers to the following texts of the Journal: 2004;30(1):56-63 2005;31(6):438-449 2010;36(6):473-483 2011;37(3):213-218 2011;37(6):451-453 2013;39(2):125-133

The following articles refer to this text: 2014;40(5):473-482; 2022;48(3):173-189; 2022;48(7):560-568

Key terms: adjustment latitude; autonomy; chronic health problem; health; health; health problem; interaction; job control; job demand; longitudinal study; older employee; older worker; physical workload; productivity loss; sickness absence; sickness absence; support; sustainable employability; work factor; work-related factor

This article in PubMed: www.ncbi.nlm.nih.gov/pubmed/23440271

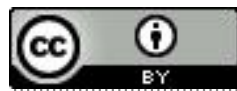




\title{
Do work factors modify the association between chronic health problems and sickness absence among older employees?
}

\author{
by Fenna RM Leijten, MSc, ${ }^{1,2}$ Swenne G van den Heuvel, PhD, ${ }^{2}$ Jan Fekke Ybema, PhD, ${ }^{2}$ Suzan J W \\ Robroek, PhD, ${ }^{1}$ Alex Burdorf, PhD ${ }^{1}$
}

\begin{abstract}
Leijten FRM, van den Heuvel SG, Ybema JF, Robroek SJW, Burdorf A. Do work factors modify the association between chronic health problems and sickness absence among older employees? Scand J Work Environ Health. 2013;39(5):477-485. doi:10.5271/sjweh.3353
\end{abstract}

\begin{abstract}
Objectives The aim of this study was to (i) assess how common chronic health problems and work-related factors predict sickness absence and (ii) explore whether work-related factors modify the effects of health problems on sickness absence.

Methods A one-year longitudinal study was conducted among employed persons aged 45-64 years from the Study on Transitions in Employment, Ability and Motivation ( $N=8984$ ). The presence of common chronic health problems and work-related factors was determined at baseline and self-reported sickness absence at one-year follow-up by questionnaire. Multinomial multivariate logistic regression analyses were conducted to assess associations between health, work factors, and sickness absence, and relative excess risk due to interaction (RERI) techniques were used to test effect modification.
\end{abstract}

Results Common health problems were related to follow-up sickness absence, most strongly to high cumulative sickness absence ( $>9$ days per year). Baseline psychological health problems were strongly related to high sickness absence at follow-up [odds ratio (OR) 3.67, 95\% confidence interval $(95 \%$ CI) $2.80-4.82$ ]. Higher job demands at baseline increased the likelihood of high sickness absence at follow-up among workers with severe headaches [RERI 1.35 (95\% CI 0.45-2.25)] and psychological health problems [RERI 3.51 ( $95 \%$ CI 0.67-6.34)] at baseline. Lower autonomy at baseline increased the likelihood of high sickness absence at follow-up among those with musculoskeletal [RERI $0.57(95 \%$ CI $0.05-1.08)$ ], circulatory [RERI $0.82(95 \%$ CI $0.00-1.63)$ ], and psychological health problems [RERI 2.94 (95\% CI 0.17-5.70)] at baseline.

Conclusions Lower autonomy and higher job demands increased the association of an array of common chronic health problems with sickness absence, and thus focus should be placed on altering these factors in order to reduce sickness absence and essentially promote sustainable employability.

Key terms adjustment latitude; autonomy; interaction; job control; job demand; longitudinal study; older worker; physical workload; productivity loss; support; sustainable employability; work-related factor.

Due to the ageing workforce and decreasing birth rates, it has become crucial to ensure older employees work productively and in good health for longer. Alongside ageing, health problems occur more often and in turn work ability can decrease (1). Poor health can lead to reduced productivity in terms of productivity loss at work, increased sickness absence, or exit from the workforce (2-4). The influence that poor health has on sickness absence differs for various types of health problems
(3-5). Work-related factors, such as autonomy, social support, and work pressure also influence productivity loss at work and sickness absence (6-9). Past findings indicate that work-related factors, such as autonomy, job satisfaction, physical load, and social support, interact with health problems in their influence on productivity outcomes (10-14).

In accordance with past findings, we hypothesize that favorable factors at work such as high support, high

1 Department of Public Health, Erasmus MC, University Medical Center, Rotterdam, The Netherlands.

2 Netherlands Organisation for Applied Scientific Research TNO, Hoofddorp, The Netherlands.

Correspondence to: Alex Burdorf, Department of Public Health, Erasmus MC, PO Box 2040, 3000 CA Rotterdam, The Netherlands. [E-mail: a.burdorf@erasmusmc.nl] 
autonomy, low job and emotional demands, and low physical load can help employees with health problems to remain productive at work and avoid or reduce sickness absence. Findings from past qualitative research $(15,16)$ support the idea that work-related factors modify the effect of health on sickness absence, but quantification of this occurrence is still lacking in the literature. Understanding the effect of work on the influence of poor health on sickness absence has important practical implications because health problems may not always be solved, but work-related factors are amendable.

Since past studies have shown that different health problems affect sickness absence to a different extent (3, 5), it is possible that effect modification of work-related factors also differs per health condition. We hypothesize that health problems will cause sickness absence if unfavorable work factors are present that trigger or aggravate the health problems or that interfere with functioning. For example, psychosocial work factors such as emotional demands and lack of support could especially modify the effects of psychological health problems on sickness absence, whereas workers with musculoskeletal disorders in physically demanding jobs may experience more limitations at work and, thus, are more likely to call in sick. Gaining such problem-specific insight is essential for the development of tailored interventions for sustainable employability, defined as maintaining a high work productivity in good health. The goals of this study were to (i) assess how health problems and work-related factors predict sickness absence and (ii) investigate whether and to what extent work-related factors modify the effects of common health problems on sickness absence.

\section{Methods}

\section{Study design}

A prospective study with a one-year follow-up was conducted within the longitudinal Study on Transition in Employment, Ability, and Motivation (STREAM) (17). In STREAM, a stratified sample of Dutch citizens aged 45-64 years complete annual online questionnaires on health, job and personal characteristics, work ability, productivity, and transitions in employment. The current study used STREAM data from 2010 (baseline) and 2011 (follow-up). In 2010, 15118 individuals participated (response $71 \%$ ), with comparable participation in the four age groups sampled: 45-49, 50-54, 55-59, and 60-64 years. In 2011, 12430 individuals participated again in STREAM (82\%). As our research questions pertained to work-related factors that are specific to workplace settings, we excluded participants if they underwent a transition in work status (employed, self-employed, not employed) between baseline and follow-up ( $\mathrm{N}=1075)$, were self-employed both years ( $\mathrm{N}=728)$, or not employed both years $(\mathrm{N}=1474)$. Of the remaining participants, 169 persons were excluded because of incomplete data, resulting in a total inclusion of 8984 participants in this study.

The Medical Ethical Committee of the Free University of Amsterdam Medical Center declared that the Medical Research Involving Human Subjects Act does not apply to the STREAM study. The Medical Ethical Committee had no objection to the execution of this research. In the information that accompanied the online questionnaire, it was emphasized that (i) the privacy of participants was guaranteed, (ii) all answers to the questions were anonymous and would be treated confidentially, and (iii) all data were stored in secured computer systems.

\section{Sickness absence}

Sickness absence was assessed at baseline and at followup with the open question: "How many work days have you, during the past twelve months, been absent due to sickness?" Three categories of cumulative sickness absence were made: none ( 0 days), low (1-9 days), and high ( $>9$ days).

\section{Health problems}

The occurrence of various health problems at baseline was assessed with the question: "Do you [currently] have one or more of the following chronic diseases, disorders, or handicaps?" (18). Of the 13 answer options, the following 7 categories were made: musculoskeletal disorders (MSD), migraine or severe headaches, circulatory diseases, respiratory diseases, digestive problems, diabetes, and psychological complaints. These health categories were not mutually exclusive. Multimorbidity was defined as the presence of $\geq 2$ health problems.

\section{Work-related factors}

Studied work-related factors included: autonomy, support, job demands, emotional demands at work, and physical workload. Autonomy was measured with five items derived from the Job Content Questionnaire (JCQ) about: making decisions, deciding the order of and speed of conducting tasks, having to find solutions, and being able to take time off (Cronbach's alpha $=0.78$ ) (19). Job demands, measured with four JCQ items, consisted of how fast, much, hard, and hectic an individual's work is (Cronbach's alpha $=0.87$ ) (19). Support was measured with four items from the Copenhagen Psychosocial Questionnaire (COPSOQ) concerning whether colleagues and supervisors are 
willing to help and listen to work-related problems (Cronbach's alpha $=0.81)(20,21)$. Emotional demands at work were also assessed with three items derived from the COPSOQ about emotionally difficult situations, emotional demands, and emotional involvement at work (Cronbach's alpha $=0.85)(20,21)$. Physical workload was assessed with five items from the Dutch Musculoskeletal Questionnaire on force exertion, static load (standing, posture, kneeling), and vibration (using tools or machines that cause vibration) (Cronbach's alpha=0.86) (22). All work-related factor items had 5 -point answer scales ranging from $1=$ (almost) never to $5=$ always. These scales were dichotomized based on the sample distribution (median values). Categories suspected of having the lowest risk for sickness absence were used as reference categories (23).

\section{Covariates}

Age, gender, and educational level were incorporated in this study as covariates. The highest level of education attained was categorized into three groups: low (lower general secondary educational, preparatory secondary vocational education), medium (intermediate vocational training, higher general secondary education, pre-university education), and high (higher vocational education, university education).

\section{Statistical analysis}

Descriptive statistics were used to report on general characteristics of the study population. Multinomial logistic regression analyses were conducted to study associations between health problems and work-related factors as independent variables at baseline with the occurrence of cumulative sickness absence during 12-month follow-up, distinguishing none (0 days) (reference), low (1-9 days), and high ( $>9$ days) cumulative sickness absence. Odds ratios (OR) and their corresponding $95 \%$ confidence intervals $(95 \% \mathrm{CI})$ were calculated. First, in model 1, analyses were conducted for each independent variable separately, adjusting for age, gender, and education, since these individual characteristics were significantly related to sickness absence. Thereafter, a multivariate analysis (model 2) using an enter method was conducted, incorporating the work-related factors, health problems, and covariates that had a significant association with either low or high cumulative sickness absence in model 1 . This procedure allows for a direct comparison between determinants of low and high sickness absence. Lastly, in model 3, baseline sickness absence was also added to the multivariate model, categorized the same way as follow-up sickness absence. This model focuses on incidence rather than occurrence of sickness absence as the dependent vari- able. As multimorbidity was defined on the basis of separate health problems, this variable was not included in either models 2 or 3 in order to avoid over adjustment.

To study whether and to what extent work-related factors modified the effect of health problems on sickness absence, interaction effects were analyzed by calculating relative excess risk due to interaction (RERI) terms and their $95 \% \mathrm{CI}$, using the delta method in Excel (Microsoft Corp, Redmond, WA, USA) (23-25). RERI are calculated with OR as estimates of relative risks $(\mathrm{RR}), \mathrm{RERI}=\mathrm{OR}_{\text {(health problem }+ \text { unfavorable work factor) }}-\mathrm{OR}_{\text {(health }}$ problem + favorable work factor) $-\mathrm{OR}_{\text {(no health problem }+ \text { unfavorable work factor) }}+$ $1(23,24)$. When RERI is not equal to zero, an additive interaction is present; RERI can range from negative infinity (negative interaction, less than additivity) to positive infinity (positive interaction, more than additivity) (23). Through this analysis the per cent increase in likelihood of sickness absence for persons with a health problem and unfavorable work-related factors as opposed to those with the health problem and favorable work-related factors was also calculated [((OR health problem + unfavorable work factor $-\mathrm{OR}$ health problem + favorable work factor $)$ $\left.\mathrm{OR}_{\text {health problem + favorable work factor }}\right) \times 100$ ]. Variables that were significantly related $(\mathrm{P}<0.05)$ to sickness absence in the multivariate analysis (model 2) were incorporated in the effect modification analyses. Analyses were done using SPSS, version 20, (SPSS Institute, Chicago, IL, USA) and Excel.

\section{Results}

\section{Descriptive information}

The study population characteristics can be found in table 1. Loss-to-follow-up was $18 \%$ for both men and women, $20 \%$ and $17 \%$ for the youngest and the oldest age groups, respectively, and $18 \%$ and $16 \%$ for low and high educated persons, respectively. Persons with high baseline cumulative sickness absence had a lossto-follow-up of $18 \%$, this was $17 \%$ for those with a low sickness absence.

Additional analyses showed that, at baseline, men were less likely than women to have cumulative sickness absence of $1-9$ days [OR 0.87 (95\% CI $0.79-0.96)$ and of $>9$ days [OR $0.90(95 \% \mathrm{CI} 0.80-1.01)$ ]. The oldest age group had less sickness absence of $1-9$ days [OR 0.58 (95\% CI 0.50-0.67)] but similar sickness absence of $>9$ days [OR 0.94 (95\% CI 0.79-1.13)] when compared to the youngest age group. Lower educated persons were more likely to have high [OR 1.43 (95\% CI 1.24-1.65)] and less likely to have low [OR 0.76 (95\% CI $0.67-$ $0.86)$ ] cumulative sickness absence. All covariates were included in the remaining analyses. 
Table 1. Demographic, health, work, and sickness absence descriptive information among $\mathrm{N}=8984$ employed older (aged 45-64) individuals.

\begin{tabular}{|c|c|c|}
\hline Variable & $\%$ & $\mathrm{~N}$ \\
\hline \multicolumn{3}{|c|}{ Age (mean $=54, \min =45, \max =64$ years) } \\
\hline $45-49$ & 25.4 & 2285 \\
\hline $50-54$ & 26.6 & 2387 \\
\hline $55-59$ & 29.8 & 2681 \\
\hline $60-64$ & 18.2 & 1631 \\
\hline Gender (female) & 43.9 & 3941 \\
\hline \multicolumn{3}{|l|}{ Educational level } \\
\hline Low & 26.6 & 2393 \\
\hline Medium & 39.0 & 3507 \\
\hline High & 34.3 & 3084 \\
\hline \multicolumn{3}{|l|}{ Health problems } \\
\hline Musculoskeletal & 32.1 & 2880 \\
\hline Circulatory & 9.6 & 861 \\
\hline Severe headaches & 8.3 & 742 \\
\hline Respiratory & 7.3 & 659 \\
\hline Diabetes & 6.6 & 592 \\
\hline Digestive & 5.9 & 529 \\
\hline Psychological & 3.9 & 354 \\
\hline Multimorbidity & 11.9 & 1067 \\
\hline No health problem & 42.2 & 3793 \\
\hline \multicolumn{3}{|l|}{ Work-related factors (median) } \\
\hline Lower autonomy (4.00) & 47.7 & 4282 \\
\hline Lower support (3.71) & 35.4 & 3176 \\
\hline Higher job demands (3.00) & 49.5 & 4446 \\
\hline Higher emotional demands (2.67) & 36.8 & 3303 \\
\hline Higher physical workload (1.40) & 47.6 & 4278 \\
\hline \multicolumn{3}{|l|}{ Baseline cumulative sickness absence } \\
\hline None ( 0 days) & 53.0 & 4762 \\
\hline Low (1-9 days) & 28.7 & 2585 \\
\hline High (>9 days) & 18.2 & 1637 \\
\hline \multicolumn{3}{|c|}{ Follow-up cumulative sickness absence } \\
\hline None ( 0 days) & 55.2 & 4960 \\
\hline Low (1-9 days) & 27.3 & 2450 \\
\hline High (>9 days) & 17.5 & 1574 \\
\hline
\end{tabular}

More than fifty per cent of the participants were not absent during the one-year follow-up, about $27 \%$ had a short cumulative sickness absence (1-9 days) and about $17 \%$ had high cumulative sickness absence ( $>9$ days) within the past year. The prevalence of sickness absence at baseline was $47 \%$ and $45 \%$ at follow-up. For both low and high sickness absence, the recurrence was approximately $46 \%$ and the incidence approximately $17 \%$.

By far the most frequently present health problem at baseline was a MSD (32.1\%), followed by circulatory diseases $(9.6 \%)$, and severe headaches $(8.3 \%)$. The same pattern was seen in the frequency of health problems at follow-up, the maximum change in prevalence between the two assessments was $0.8 \%$. Multiple health problems were present in $11.9 \%$ of the study population at baseline, often combinations of MSD with: migraines $(4.0 \%)$, heart disease $(3.4 \%)$, and respiratory problems $(3.2 \%)$.
All work-related factors at baseline were marginally interrelated (Spearman's rho correlations $<0.27$ ). Workrelated factors were relatively stable at baseline and follow-up and the proportion of persons with recurrent (un)favorable work factors ranged from 69\% (emotional demands) to $87 \%$ (physical work load).

\section{Health problems and sickness absence}

Figure 1 depicts the distribution of sickness absence among persons with common health problems. High sickness absence was most common among persons with psychological complaints (38\%). Table 2 shows that the presence of a health problem at baseline was related to an increased likelihood of sickness absence during follow-up (models 1 and 2). The relationship between health problems and sickness absence was stronger with high than low cumulative sickness absence. After adjustment for baseline sickness absence (model 3), all health problems remain statistically significantly associated with high sickness absence. Overall, the associations between health problems and sickness absence were marginally reduced after adjustment for baseline sickness absence (maximum OR reduction 26\%).

\section{Work-related factors and sickness absence}

All work-related factors were related to follow-up cumulative sickness absence (table 2). After adjusting for age, gender, educational level, and health problems, lower autonomy [OR 1.30 (95\% CI 1.15-1.47)] and higher job demands [OR $1.20(95 \%$ CI 1.06-1.36)] were related to high cumulative sickness absence (model 2). Adjustment for baseline sickness absence decreased these associations (OR) by $<10 \%$ (model 3 ).

\section{Interaction work-related factors and health}

Figure 2 shows that lower autonomy and higher job demands were important work-related factors that interacted with common health problems. Interaction effects were not observed for low cumulative sickness absence (for numerical details see supplementary table A in the Appendix). Within persons with musculoskeletal [RERI 0.57 (95\% CI $0.05-1.08)$ ], circulatory [RERI $0.82(95 \%$ CI 0.00-1.63)], psychological [RERI 2.94 (95\% CI $0.17-$ 5.70)], and a multimorbidity of health problems [RERI 1.43 (95\% CI 0.48-2.38)], lower autonomy increased the likelihood of high cumulative sickness absence (figure 2 and table 3).Within persons with a multimorbidity of health problems, lower autonomy increased the likelihood of high cumulative sickness absence by $78 \%$. For those individuals with psychological health complaints, this increase in likelihood of high cumulative sickness absence was even higher, at $94 \%$ (see table 3). 


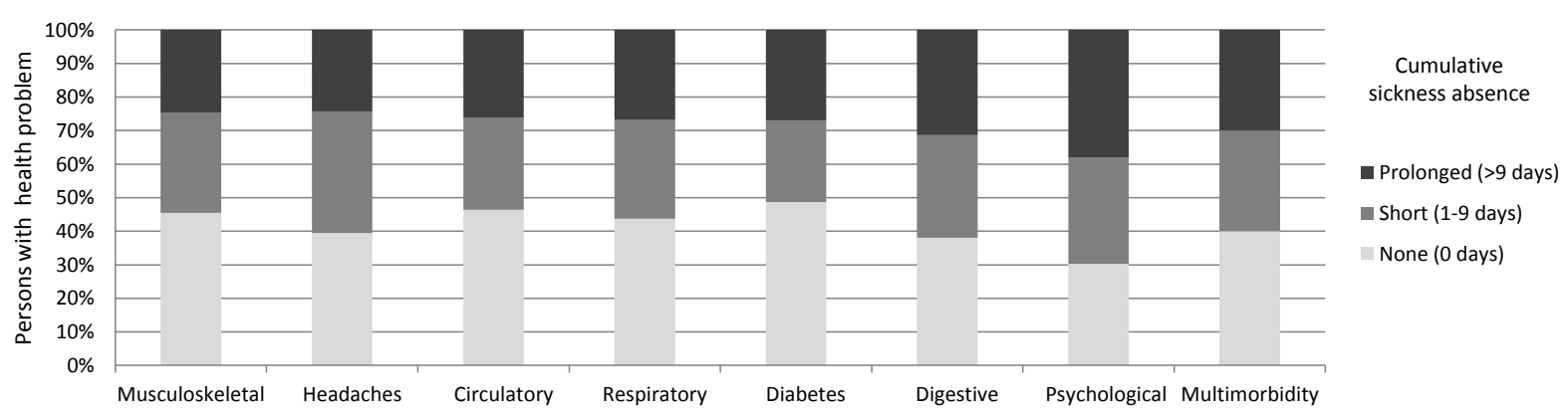

Figure 1. Occurrence of self-reported sickness absence over the past 12 months amongst older (aged 45-64) employees with common health problems $(\mathrm{N}=8984)$.

Table 2. Associations between health, work-related factors, and cumulative self-reported sickness absence in a sample of older (aged 45-64) employees ( $\mathrm{N}=8984$ ). [MSD=musculoskeletal disorders; OR=0dds ratio; $95 \% \mathrm{Cl}=95 \%$ confidence interval]

\begin{tabular}{|c|c|c|c|c|c|c|c|c|c|c|c|c|}
\hline & \multicolumn{4}{|c|}{ Model $1^{\mathrm{a}}$} & \multicolumn{4}{|c|}{ Model $2{ }^{b}$} & \multicolumn{4}{|c|}{ Model $3^{c}$} \\
\hline & \multicolumn{2}{|c|}{ Low (1-9 days) } & \multicolumn{2}{|c|}{ High (>9 days) } & \multicolumn{2}{|c|}{ Low (1-9 days) } & \multicolumn{2}{|c|}{ High (>9 days) } & \multicolumn{2}{|c|}{ Low (1-9 days) } & \multicolumn{2}{|c|}{ High (>9 days) } \\
\hline & OR & $95 \% \mathrm{Cl}$ & OR & $95 \% \mathrm{Cl}$ & $\overline{\mathrm{OR}}$ & $95 \% \mathrm{Cl}$ & $\overline{\mathrm{OR}}$ & $95 \% \mathrm{Cl}$ & $\mathrm{OR}$ & $95 \% \mathrm{Cl}$ & OR & $95 \% \mathrm{Cl}$ \\
\hline $\begin{array}{l}\text { Work-related factors } \\
\text { Low autonomy }\end{array}$ & 109 & $099-120$ & 143 & $127-160$ & 111 & $100-123$ & 130 & $115-147$ & 105 & $094-117$ & 118 & $104-135$ \\
\hline Low support & 0.88 & $0.80-0.98$ & $\begin{array}{l}1.40 \\
1.05\end{array}$ & $0.93-1.18$ & 0.85 & $0.76-0.94$ & 0.94 & $0.84-1.07$ & $\begin{array}{l}1.05 \\
0.87\end{array}$ & $\begin{array}{l}0.94-1.11 \\
0.78-0.97\end{array}$ & $\begin{array}{l}1.18 \\
0.99\end{array}$ & $\begin{array}{l}1.04-1.35 \\
0.87-1.13\end{array}$ \\
\hline High job demands & 1.11 & $1.00-1.22$ & 1.32 & $1.17-1.48$ & 1.09 & $0.98-1.21$ & 1.20 & $1.06-1.36$ & 1.06 & $0.95-1.18$ & 1.13 & $0.99-1.29$ \\
\hline High emotional demands & 1.12 & $1.01-1.24$ & 1.32 & $1.17-1.49$ & 1.07 & $0.96-1.19$ & 1.08 & $0.95-1.23$ & 1.06 & $0.95-1.19$ & 1.07 & $0.93-1.23$ \\
\hline High physical load & 0.87 & $0.79-0.96$ & 1.24 & $1.10-1.39$ & 0.80 & $0.72-0.89$ & 1.06 & $0.93-1.20$ & 0.80 & $0.72-0.90$ & 1.04 & $0.91-1.19$ \\
\hline \multicolumn{13}{|l|}{ Health problems } \\
\hline MSD & 1.55 & $1.40-1.73$ & 2.26 & $2.00-2.54$ & 1.48 & $1.33-1.65$ & 1.98 & $1.75-2.24$ & 1.32 & $1.18-1.48$ & 1.63 & $1.43-1.86$ \\
\hline Headaches & 1.84 & $1.54-2.19$ & 2.02 & $1.66-2.46$ & 1.68 & $1.41-2.01$ & 1.59 & $1.29-1.95$ & 1.47 & $1.22-1.76$ & 1.31 & $1.05-1.64$ \\
\hline Circulatory & 1.34 & $1.13-1.60$ & 1.96 & $1.64-2.34$ & 1.32 & $1.11-1.57$ & 1.79 & $1.49-2.16$ & 1.14 & $0.95-1.36$ & 1.37 & $1.12-1.68$ \\
\hline Respiratory & 1.38 & $1.14-1.67$ & 2.07 & $1.69-2.52$ & 1.28 & $1.06-1.56$ & 1.75 & $1.42-2.15$ & 1.11 & $0.91-1.36$ & 1.39 & $1.11-1.74$ \\
\hline Digestive & 1.68 & $1.36-2.0$ & 2.76 & $2.23-3$. & 1.4 & $1.17-1.8$ & 2.07 & & 1.22 & & 1.62 & $1.27-2.07$ \\
\hline Diabetes & 1.09 & $0.88-1.34$ & 1.77 & $1.44-2.17$ & 1.03 & $0.83-1.27$ & 1.55 & $1.25-1.93$ & 0.94 & $0.75-1.17$ & 1.36 & $1.07-1.71$ \\
\hline Psychological & 2.16 & $1.64-2.83$ & 4.34 & $3.34-5.65$ & 1.98 & $1.51-2.61$ & 3.67 & $2.80-4.82$ & 1.45 & $1.09-1.94$ & 2.28 & $1.70-3.07$ \\
\hline Multimorbidity & 1.53 & $1.31-1.79$ & 2.70 & $2.30-3.16$ & & & & & & & & \\
\hline
\end{tabular}

a Analyses adjusted for covariates (ie, age, gender, education).

${ }^{b}$ Analysis adjusted for covariates, work-related factors, and all health problems except multimorbidity.

${ }^{c}$ Analysis adjusted for covariates, work-related factors, all health problems except multimorbidity, and baseline sickness absence.

Higher job demands also strengthened the association of severe headaches, psychological, and a multimorbidity of health problems with high cumulative sickness absence. For persons with psychological complaints, higher as opposed to lower job demands were associated with a relative excess risk of high sickness absence of 3.51 (95\% CI 0.67-6.34), the presence of higher job demands increased the likelihood of high cumulative sickness absence by $115 \%$ (see table 3 ).

\section{Discussion}

The presence of common health problems at baseline was associated with sickness absence at one-year follow-up, especially of $>9$ days. Lower autonomy and higher job demands solely related to the likelihood of high cumulative sickness absence and interacted with various health problems. Among persons with psychological complaints, MSD, severe headaches, circulatory problems, and a multimorbidity of health problems at baseline, lower autonomy and higher job demands increased the likelihood of high cumulative sickness absence at follow-up.

In this study the modifying effects of autonomy and job demands on the relation between commonly occurring chronic health problems and sickness absence have been explicitly quantified through interaction effect analyses. The proportion of the combined effects of the work factors and health problems on sickness absence that was due to the interaction [attributable proportion (AP)=RERI/ $\mathrm{OR}_{\text {health problem + unfavorable work factor }}$ ranged from $0.18(\mathrm{MSD} \times$ autonomy) to 0.50 (psychological $\times$ job demands) (pos- 


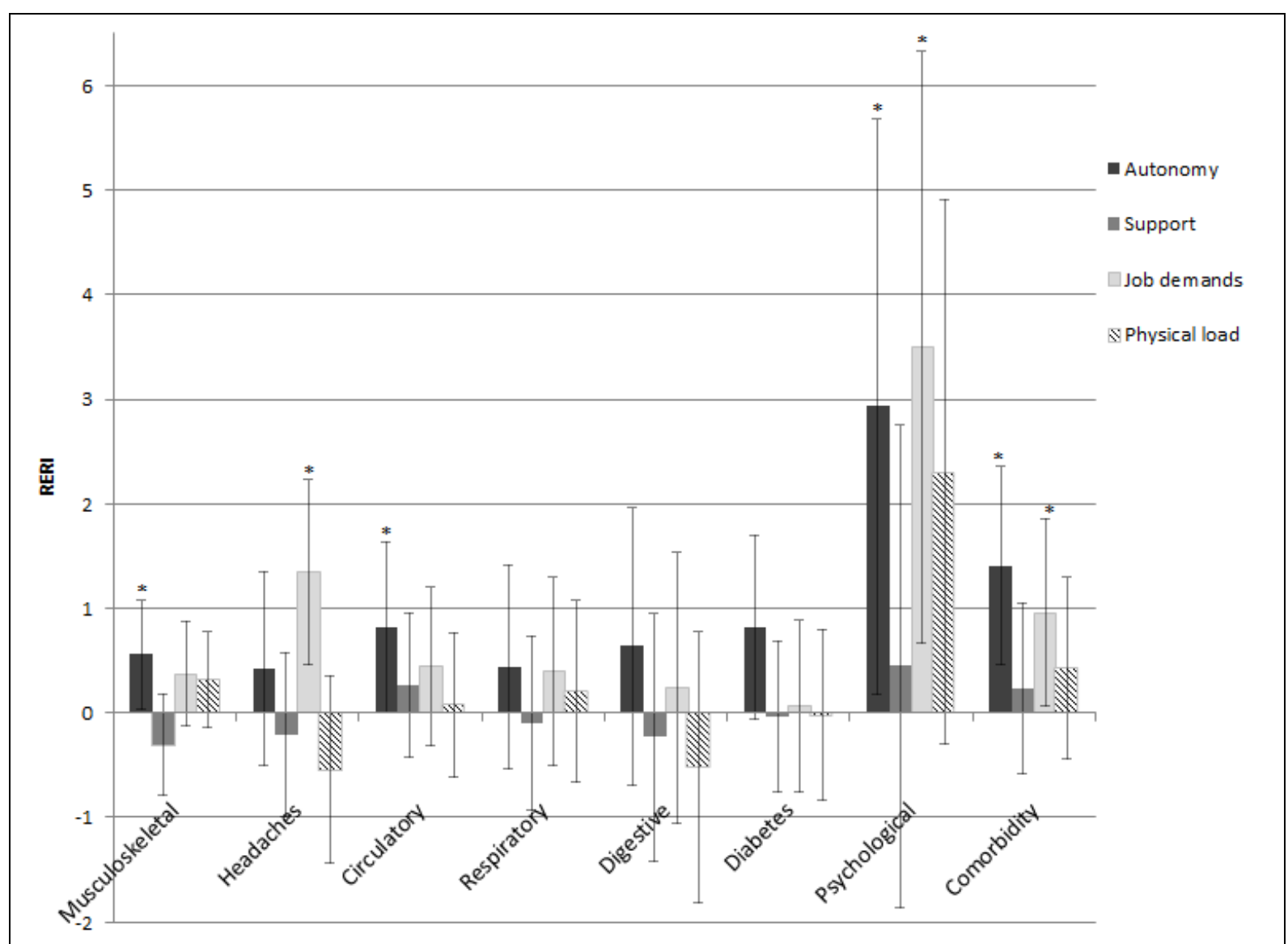

Figure 2. Relative excess risk due to interaction (RERI) of health and work-related factors on high ( $>9$ days) cumulative sickness absence during one-year follow-up, after adjustment for age, gender, and education. ${ }^{\star}$ Statistically significant $P<0.05$.

sible AP range $=-1-1)(23)$. The risk of lower autonomy and higher job demands for sickness absence has been found in other, mostly cross-sectional, studies $(9,11,12)$. Results from past findings also suggest that work-related factors play a role in the health-productivity loss association, but have looked solely at physical health problems instead of at a wide array of common health problems as the current study does $(10,13)$. Because autonomy and job demands are such important effect modifiers, it is an imperative that employers focus on these work-related factors in promoting sustainable employability.

Of all health problems, psychological health complaints had the strongest association with sickness absence after adjustment for baseline sickness absence (OR 2.28). This result is in line with findings that suggest that specifically bipolar, major depressive, and panic disorders are strongly associated with sickness absence on the population level (5). A recent study has also found that an increase in psychological health problems amongst older employees leads to disability retirement (3).

Psychological, physical, and a multimorbidity of health problems all interacted with job demands and autonomy in their associations with sickness absence. Work-related factors can modify the effect of health problems on sickness absence by supporting active and successful coping and adaptations, that will enable an individual to keep working productively as was found in a recent interview study also carried out within STREAM (16). It may be hypothesized that psychosocial workrelated factors are important because they allow an individual to exert control over how his or her work is conducted and inherently how adjustments therein can be made. Aspects of the Illness Flexibility model, and findings from the aforementioned interview study, are in line with this (12). The results also point to the relevance of internal motivation as a potential prerequisite of making such alterations $(12,16)$. Future research should thus corroborate whether favorable work factors are sufficient in reducing sickness absence or whether motivational factors further moderate this relationship.

Because physical workload was not associated with high sickness absence, some extra explorative analyses were conducted. Separate analyses for each item of physical load showed comparable results, hence, the 
Table 3. Interaction effects of work-related factors and health on high cumulative sickness absence, after adjustment for age, gender, and education ( $\mathrm{N}=6534)$. Excluding persons with low cumulative sickness absence $(\mathrm{N}=2450)$. [MSD=musculoskeletal disorders; OR=odds ratio; $95 \% \mathrm{Cl}=95 \%$ confidence interval.]

\begin{tabular}{|c|c|c|c|c|c|c|}
\hline $\begin{array}{l}\text { Health } \\
\text { problem }\end{array}$ & $\begin{array}{l}\text { Work-related } \\
\text { factor }\end{array}$ & $\mathrm{N}$ & OR & $95 \% \mathrm{Cl}$ & RERI & $95 \% \mathrm{Cl}$ \\
\hline $\begin{array}{l}\text { MSD } \\
\text { Not present } \\
\text { Not present } \\
\text { Present } \\
\text { Present }\end{array}$ & $\begin{array}{c}\text { Autonomy } \\
\text { Higher } \\
\text { Lower } \\
\text { Higher } \\
\text { Lower }\end{array}$ & $\begin{array}{r}2446 \\
2069 \\
979 \\
1040\end{array}$ & $\begin{array}{l}1.00 \\
1.37 \\
2.19 \\
3.12\end{array}$ & $\begin{array}{l}1.18-1.59 \\
1.84-2.60 \\
2.65-3.69\end{array}$ & 0.57 & $0.05-1.08$ \\
\hline $\begin{array}{l}\text { Severe } \\
\text { headaches } \\
\text { Not present } \\
\text { Not present } \\
\text { Present } \\
\text { Present }\end{array}$ & $\begin{array}{l}\text { Job } \\
\text { demands } \\
\text { Lower } \\
\text { Higher } \\
\text { Lower } \\
\text { Higher }\end{array}$ & $\begin{array}{r}3121 \\
2942 \\
222 \\
249\end{array}$ & $\begin{array}{l}1.00 \\
1.25 \\
1.52 \\
3.12\end{array}$ & $\begin{array}{l}1.11-1.41 \\
1.12-2.06 \\
2.39-4.07\end{array}$ & 1.35 & $0.45-2.25$ \\
\hline $\begin{array}{l}\text { Circulatory } \\
\text { disorders } \\
\text { Not present } \\
\text { Not present } \\
\text { Present } \\
\text { Present }\end{array}$ & $\begin{array}{l}\text { Higher } \\
\text { Lower } \\
\text { Higher } \\
\text { Lower }\end{array}$ & $\begin{array}{r}3102 \\
2806 \\
323 \\
303\end{array}$ & $\begin{array}{l}1.00 \\
1.39 \\
1.76 \\
2.97\end{array}$ & $\begin{array}{l}1.23-1.57 \\
1.36-2.28 \\
2.32-3.79\end{array}$ & 0.82 & $0.00-1.63$ \\
\hline $\begin{array}{l}\text { Psychological } \\
\text { complaints } \\
\text { Not present } \\
\text { Not present } \\
\text { Present } \\
\text { Present }\end{array}$ & $\begin{array}{l}\text { Autonomy } \\
\text { Higher } \\
\text { Lower } \\
\text { Higher } \\
\text { Lower }\end{array}$ & $\begin{array}{r}3320 \\
2973 \\
105 \\
136\end{array}$ & $\begin{array}{l}1.00 \\
1.38 \\
3.53 \\
6.85\end{array}$ & $\begin{array}{l}1.23-1.55 \\
2.38-5.24 \\
4.78-9.82\end{array}$ & 2.94 & $0.17-5.70$ \\
\hline $\begin{array}{l}\text { Not present } \\
\text { Not present } \\
\text { Present } \\
\text { Present }\end{array}$ & $\begin{array}{l}\text { Job demands } \\
\text { Lower } \\
\text { Higher } \\
\text { Lower } \\
\text { Higher }\end{array}$ & $\begin{array}{r}3232 \\
3061 \\
111 \\
130\end{array}$ & $\begin{array}{l}1.00 \\
1.27 \\
3.27 \\
7.04\end{array}$ & $\begin{array}{r}1.13-1.43 \\
2.22-4.80 \\
4.86-10.21\end{array}$ & 3.51 & $0.67-6.34$ \\
\hline $\begin{array}{l}\text { Multi- } \\
\text { morbidity }\end{array}$ & Autonomy & & & & 1.43 & $0.48-2.38$ \\
\hline Not present & Higher & 3070 & 1.00 & & & \\
\hline Not present & Lower & 2707 & 1.34 & & & \\
\hline Present & Higher & 353 & 2.28 & $1.80-2.89$ & & \\
\hline Present & $\begin{array}{c}\text { Lower } \\
\text { Job demands }\end{array}$ & 404 & 4.05 & $3.26-5.03$ & 1.01 & $0.11-1.91$ \\
\hline $\begin{array}{l}\text { Not present } \\
\text { Not present } \\
\text { Present } \\
\text { Present }\end{array}$ & $\begin{array}{l}\text { Lower } \\
\text { Higher } \\
\text { Lower } \\
\text { Higher }\end{array}$ & $\begin{array}{r}2994 \\
2785 \\
349 \\
406\end{array}$ & $\begin{array}{l}1.00 \\
1.26 \\
2.43 \\
3.70\end{array}$ & $\begin{array}{l}1.11-1.44 \\
1.92-3.08 \\
2.98-4.60\end{array}$ & & \\
\hline
\end{tabular}

scale construction cannot explain the lack of an association. Further, because the multivariate analyses corrected for educational level it is possible that overcorrection occurred, but when the analyses were repeated without the inclusion of educational level, the same non-significant effects were found. Past findings on the role of physical load in productivity loss have also been inconclusive (4). Because the participants in STREAM are $\geq 45$ years of age, it is possible that persons who worked in jobs that required a higher physical load - but could not handle this due to poor health - had already switched careers at a younger age, and thus the healthy worker effect might explain our findings.
There are limitations in this study to be mentioned. Because sickness absence was measured at both baseline and follow-up, we assessed the association of health and work-related factors with both incidence (model 3) and occurrence (models 1 and 2, interaction analyses) of sickness absence. Since sickness absence in both models 2 and 3 had similar determinants, the interaction effect analyses were limited to the occurrence of sickness absence because the current study had less discriminatory power to also investigate interaction for incident cases.

Effect modification was assessed with RERI interaction effect analyses. Based on our hypotheses, we presumed that work-related factors modified the effects of health on sickness absence. A reversed scenario, in which health moderates the effects of work factors on sickness absence, cannot be excluded on the basis of interaction effect analyses. However, our primary hypothesis was that health problems precede sickness absence, as presented in the introduction.

As many variables were included in the analyses, there is a possibility of finding effects per chance. We, however, chose to analyze the effects of many different common health problems and work-related factors on sickness absence in order to assess consistent patterns and effects; autonomy and job demands were important effect modifiers for a variety of health problems.

Work-related factors were dichotomized as higher or lower on the basis of median values because scales were ordinal and some scores were much more frequent than others, for example low physical workload. Making different groups for each of the 5-point answers would have led to a large reduction of power. Dichotomization had the potential downside that participants were categorized as higher or lower, which may not have reflected their scores on the scale labels. For example, the median cut-off point for higher physical load was 1.40 , which is according to the labels everything but "(almost) never"; thus "rarely", "sometimes", "often", and "(almost) always" were clustered together. To control the accuracy of findings, analyses were done comparing participants with the lowest and highest tertile work-related factor scale scores. Because these analyses resulted in very similar findings to the median value analyses, we chose to keep the median as a cut-off point.

The self-reported health problem item may be flawed in that the health problems were a combination of disorders and complaints, and the question did not specify whether the problem was diagnosed by a physician. Nonetheless, the health problems were clear predictors for sickness absence. Self-reporting of sickness absence over a 12-month period has been found to concur with registered sickness absence. As sickness absence days increase, however, the accuracy of self-reporting decreases $(27,28)$. Since high sickness 
absence was defined by any number of days $>9$ in our study, we assume that such inaccuracies did not influence our findings.

Based on findings from the current study, we conclude that autonomy and job demands have a moderating effect on the association between common chronic health problems and sickness absence. Encouraging lower job demands and higher autonomy can help to reduce sickness absence in spite of the presence of health problems. Therefore, work-related factors are deemed to be essential in the promotion of sustainable employment and relevant for interventions for older employees with health problems.

\section{Acknowledgements}

The current study was conducted with financial support from the Erasmus Medical Center, TNO, and the Dutch Ministry of Social Affairs and Employment.

The authors declare no conflict of interest.

\section{References}

1. Härmä M. Adding more years to the work careers of an aging workforce - what works? Scand J Work Environ Health. 2011;37(6):451-3. http://dx.doi.org/10.5271/sjweh.3198.

2. Robroek, SJW, Schuring M, Croezen, S, Stattin M, Burdorf A. Poor health, unhealthy behaviors, and unfavorable work characteristics influence pathways of exit from paid employment among older workers in Europe: a four year follow-up study. Scand J Work Environ Health. 2013;39(2):125-33. http://dx.doi.org/10.5271/sjweh.3319.

3. Laaksonen M, Kääriä SM, Leino-Arjas P, Lahelma E. Different domains of health functioning as predictors of sickness absence--a prospective cohort study. Scand J Work Environ Health. 2011;37(3):213-8. http://dx.doi.org/10.5271/ sjweh.3131.

4. Alavinia SM, Molenaar D, Burdorf A. Productivity loss in the workforce: associations with health, work demands, and individual characteristics. Am J Ind Med. 2009;52(1):49-56. http://dx.doi.org/10.1002/ajim.20648.

5. de Graaf R, Tuithof M, van Dorsselaer S, ten Have M. Comparing the effects on work performance of mental and physical disorders. Soc Psychiatry Psychiatr Epidemiol. 2012;47(11):1873-83. http://dx.doi.org/10.1007/s00127012-0496-7.

6. Aronsson G, Gustafsson K. Sickness presenteeism: prevalence, attendance-pressure factors, and an outline of a model for research. J Occup Environ Med. 2005;47(9):958-66. http:// dx.doi.org/10.1097/01.jom.0000177219.75677.17.

7. Labriola M, Christensen KB, Lund T, Nielsen ML,
Diderichsen F. Multilevel analysis of workplace and individual risk factors for long-term sickness absence. J Occup Environ Med. 2006;48(9):923-9. http://dx.doi.org/10.1097/01. jom.0000229783.04721.d2.

8. IJzelenberg W, Molenaar D, Burdorf A. Different risk factors for musculoskeletal complaints and musculoskeletal sickness absence. Scand J Work Environ Health. 2004;30(1):56-63. http://dx.doi.org/10.5271/sjweh.765.

9. van den Heuvel SG, Geuskens GA, Hooftman WE, Koppes LL, van den Bossche SN. Productivity loss at work; health-related and work-related factors. J Occup Rehabil. 2010;20(3):331-9. http://dx.doi.org/10.1007/s10926-009-9219-7.

10. Geuskens GA, Hazes JM, Barendregt PJ, Burdorf A. Predictors of sick leave and reduced productivity at work among persons with early inflammatory joint conditions. Scand J Work Environ Health. 2008;34(6):420-9. http://dx.doi.org/10.5271/ sjweh.1298.

11. van den Berg TI, Robroek SJ, Plat JF, Koopmanschap MA, Burdorf A. The importance of job control for workers with decreased work ability to remain productive at work. Int Arch Occup Environ Health. 2011;84(6):705-12. http://dx.doi. org/10.1007/s00420-010-0588-1.

12. Johansson G, Lundberg I. Adjustment latitude and attendance requirements as determinants of sickness absence or attendance. Empirical tests of the illness flexibility model. Soc Sci Med. 2004;58(10):1857-68. http://dx.doi.org/10.1016/ S0277-9536(03)00407-6.

13. Hoogendoorn WE, Bongers PM, de Vet HCW, Ariëns GAM, van Mechelen W, Bouter LM. High physical work load and low job satisfaction increase the risk of sickness absence due to low back pain: results of a prospective cohort study. Occup Environ Med. 2002;59(5):323-8. http://dx.doi.org/10.1136/ oem.59.5.323.

14. Meerding WJ, Ijzelenberg W, Koopmanschap MA, Severens JL, Burdorf A. Health problems lead to considerable productivity loss at work among workers with high physical load jobs. J Clin Epidemiol. 2005;58(5):517-23. http://dx.doi. org/10.1016/j.jclinepi.2004.06.016.

15. Young AE. Return to work following disability occupational injury--facilitators of employment continuation. Scand J Work Environ Health. 2010;36(6):473-83. http://dx.doi. org/10.5271/sjweh.2986.

16. Leijten F, van den Heuvel S, Geuskens G, Ybema JF, de Wind A, Burdorf A, Robroek S. How do older employees with health problems remain productive at work?: A qualitative study. J Occup Rehabil. 2013;23(1):115-24. http://dx.doi. org/10.1007/s10926-012-9390-0.

17. Ybema JF, Geuskens GA, van den Heuvel SG. [Study on transitions in employment, ability, and motivation (STREAM): Methodology and first results]. Hoofddorp: TNO; 2011. Dutch.

18. Koppes LLJ, de Vroome EMM, Mol MEM, Janssen BJM, van den Bossche SNJ. [Netherlands working conditions survey 2009: Methodology and overall results]. Hoofddorp: TNO; 2010. Dutch.

19. Karasek R, Brisson C, Kawakami N, Houtman I, Bongers P, 
Amick B. The Job Content Questionnaire (JCQ): an instrument for internationally comparative assessments of psychosocial job characteristics. J Occup Health Psychol. 1998;3(4):32255. http://dx.doi.org/10.1037/1076-8998.3.4.322.

20. Kristensen TS, Hannerz H, Høgh A, Borg V. The Copenhagen Psychosocial Questionnaire--a tool for the assessment and improvement of the psychosocial work environment. Scand J Work Environ Health. 2005;31(6):438-49. http://dx.doi. org/10.5271/sjweh.948.

21. Kristensen TS, Borg V. Copenhagen Psychosocial Questionnaire (COPSOQ). Copenhagen: National Institute of Occupational Health; 2010.

22. Bot SDM, Terwee CB, van der Windt DAWM, Feleus A, Bierma-Zeinstra SM, Knol DL, et al. Internal consistency and validity of a new physical workload questionnaire. Occup Environ Med. 2004;61(12):980-6. http://dx.doi.org/10.1136/ oem.2003.011213.

23. Knol MJ, VanderWeele TJ, Groenwold RH, Klungel $\mathrm{OH}$, Rovers MM, Grobbee DE. Estimating measures of interaction on an additive scale for preventive exposures. Eur J Epidemiol. 2011;26(6):433-8. http://dx.doi.org/10.1007/s10654-0119554-9.

24. Andersson T, Alfredsson L, Källberg H, Zdravkovic S, Ahlbom A. Calculating measures of biological interaction. Eur $\mathrm{J}$
Epidemiol. 2005;20(7):575-9. http://dx.doi.org/10.1007/ s10654-005-7835-x.

25. Hosmer DW, Lemeshow S. Confidence interval estimation of interaction. Epidemiology. 1992;3(5):452-6. http://dx.doi. org/10.1097/00001648-199209000-00012.

26. Andersen MF, Nielsen KM, Brinkmann S. Meta-synthesis of qualitative research on return to work among employees with common mental disorders. Scand J Work Environ Health. 2012;38(2):93-104.

27. Ferrie K, Kivimäki M, Head J, Shipley M, Vahtera J, Marmot M. A comparison of self-reported sickness absence with absences recorded in employers' registers: evidence from the Whitehall II study. Occup Environ Med. 2005;62(2):74-9. http://dx.doi.org/10.1136/oem.2004.013896.

28. Stapelfeldt CM, Jensen C, Andersen NT, Fleten N, Nielsen CV. Validation of sick leave measures: self-reported sick leave and sickness benefit data from a Danish national register compared to multiple workplace-registered sick leave spells in a Danish municipality. BMC Public Health. 2012;12:661. http://dx.doi. org/10.1186/1471-2458-12-661.

Received for publication: 16 October 2012

Supplementary table A. Effect modification, expressed as relative excess risk due to interaction (RERI), of work-related factors on the influence of health on cumulative sickness absence (SA) in older (aged 45-64) employees ( $N=8984)$. Adjusted for age, gender, and educational level. [ $95 \% \mathrm{Cl}=95 \%$ confidence interval].

\begin{tabular}{|c|c|c|c|c|c|c|c|c|}
\hline \multirow{2}{*}{$\begin{array}{l}\text { Level of SA a by } \\
\text { health problem }\end{array}$} & \multicolumn{2}{|c|}{ Autonomy } & \multicolumn{2}{|c|}{ Support } & \multicolumn{2}{|c|}{ Job demands } & \multicolumn{2}{|c|}{ Physical load } \\
\hline & RERI & $95 \% \mathrm{Cl}$ & RERI & $95 \% \mathrm{Cl}$ & RERI & $95 \% \mathrm{Cl}$ & RERI & $95 \% \mathrm{Cl}$ \\
\hline \multicolumn{9}{|l|}{ MSD } \\
\hline $\begin{array}{l}\text { Low } \\
\text { High }\end{array}$ & $\begin{array}{l}0.24 \\
0.57\end{array}$ & $\begin{array}{r}-0.06-0.53 \\
0.05-1.08\end{array}$ & $\begin{array}{l}-0.02 \\
-0.30\end{array}$ & $\begin{array}{l}-0.31-0.27 \\
-0.79-0.19\end{array}$ & $\begin{array}{r}-0.13 \\
0.37\end{array}$ & $\begin{array}{l}-0.45-0.19 \\
-0.12-0.87\end{array}$ & $\begin{array}{l}0.23 \\
0.33\end{array}$ & $\begin{array}{l}-0.02-0.47 \\
-0.13-0.80\end{array}$ \\
\hline \multicolumn{9}{|l|}{ Severe headaches } \\
\hline $\begin{array}{l}\text { Low } \\
\text { High }\end{array}$ & $\begin{array}{r}-0.23 \\
0.42\end{array}$ & $\begin{array}{l}-0.88-0.43 \\
-0.51-1.35\end{array}$ & $\begin{array}{r}0.24 \\
-0.21\end{array}$ & $\begin{array}{l}-0.36-0.85 \\
-0.98-0.57\end{array}$ & $\begin{array}{l}0.48 \\
1.35\end{array}$ & $\begin{array}{r}-0.20-1.15 \\
0.45-2.25\end{array}$ & $\begin{array}{l}-0.18 \\
-0.53\end{array}$ & $\begin{array}{l}-0.78-0.42 \\
-1.43-0.36\end{array}$ \\
\hline \multicolumn{9}{|l|}{ Circulatory } \\
\hline $\begin{array}{l}\text { Low } \\
\text { High }\end{array}$ & $\begin{array}{l}0.14 \\
0.82\end{array}$ & $\begin{array}{r}-0.34-0.62 \\
0.00-1.63\end{array}$ & $\begin{array}{r}-0.10 \\
0.28\end{array}$ & $\begin{array}{r}-0.54-0.34 \\
-0.42--0.97\end{array}$ & $\begin{array}{l}0.21 \\
0.44\end{array}$ & $\begin{array}{l}-0.27-0.69 \\
-0.32-1.21\end{array}$ & $\begin{array}{r}-0.16 \\
0.08\end{array}$ & $\begin{array}{l}-0.59-0.27 \\
-0.66-0.83\end{array}$ \\
\hline \multicolumn{9}{|l|}{ Respiratory } \\
\hline $\begin{array}{l}\text { Low } \\
\text { High }\end{array}$ & $\begin{array}{l}0.51 \\
0.46\end{array}$ & $\begin{array}{l}-0.05-1.06 \\
-0.51-1.44\end{array}$ & $\begin{array}{l}-0.20 \\
-0.12\end{array}$ & $\begin{array}{l}-0.69-0.29 \\
-0.93-0.69\end{array}$ & $\begin{array}{l}0.16 \\
0.43\end{array}$ & $\begin{array}{l}-0.38-0.71 \\
-0.47-1.33\end{array}$ & $\begin{array}{l}0.26 \\
0.19\end{array}$ & $\begin{array}{l}-0.22-0.74 \\
-0.69-1.06\end{array}$ \\
\hline \multicolumn{9}{|l|}{ Digestive } \\
\hline $\begin{array}{l}\text { Low } \\
\text { High }\end{array}$ & $\begin{array}{r}-0.75 \\
0.64\end{array}$ & $\begin{array}{l}-1.52-0.03 \\
-0.69-1.98\end{array}$ & $\begin{array}{l}-0.12 \\
-0.23\end{array}$ & $\begin{array}{l}-0.80-0.56 \\
-1.42-0.96\end{array}$ & $\begin{array}{r}-0.09 \\
0.24\end{array}$ & $\begin{array}{l}-0.84-0.67 \\
-1.07-1.55\end{array}$ & $\begin{array}{l}-0.20 \\
-0.52\end{array}$ & $\begin{array}{l}-0.87-0.47 \\
-1.82-0.78\end{array}$ \\
\hline \multicolumn{9}{|l|}{ Diabetes } \\
\hline $\begin{array}{l}\text { Low } \\
\text { High }\end{array}$ & $\begin{array}{l}0.16 \\
0.82\end{array}$ & $\begin{array}{l}-0.32-0.65 \\
-0.06-1.70\end{array}$ & $\begin{array}{l}-0.10 \\
-0.08\end{array}$ & $\begin{array}{l}-0.53-0.34 \\
-0.80-0.63\end{array}$ & $\begin{array}{l}0.31 \\
0.07\end{array}$ & $\begin{array}{l}-0.17-0.80 \\
-0.76-0.89\end{array}$ & $\begin{array}{r}0.08 \\
-0.01\end{array}$ & $\begin{array}{l}-0.35-0.50 \\
-0.82-0.79\end{array}$ \\
\hline \multicolumn{9}{|l|}{ Psychological } \\
\hline $\begin{array}{l}\text { Low } \\
\text { High }\end{array}$ & $\begin{array}{l}1.09 \\
2.94\end{array}$ & $\begin{array}{r}-0.15-2.32 \\
0.17-5.70\end{array}$ & $\begin{array}{r}-0.02 \\
0.46\end{array}$ & $\begin{array}{l}-1.13-1.09 \\
-1.85-2.76\end{array}$ & $\begin{array}{l}0.31 \\
3.51\end{array}$ & $\begin{array}{r}-0.95-1.56 \\
0.67-6.34\end{array}$ & $\begin{array}{l}0.55 \\
2.30\end{array}$ & $\begin{array}{l}-0.56-1.66 \\
-0.30-4.90\end{array}$ \\
\hline \multicolumn{9}{|l|}{ Multimorbidity } \\
\hline $\begin{array}{l}\text { Low } \\
\text { High }\end{array}$ & $\begin{array}{l}0.34 \\
1.43\end{array}$ & $\begin{array}{r}-0.14-0.82 \\
0.48-2.38\end{array}$ & $\begin{array}{r}-0.03 \\
0.21\end{array}$ & $\begin{array}{l}-0.47-0.42 \\
-0.60-1.02\end{array}$ & $\begin{array}{l}0.17 \\
1.01\end{array}$ & $\begin{array}{r}-0.34-0.68 \\
0.11-1.91\end{array}$ & $\begin{array}{l}0.15 \\
0.41\end{array}$ & $\begin{array}{l}-0.29-0.58 \\
-0.46-1.29\end{array}$ \\
\hline
\end{tabular}

a Low: 1-9 days, high: $>9$ days. 